\title{
Investigation of Spinal Posture Signatures and Ground Reaction Forces During Landing in Elite Female Gymnasts
}

\author{
Melanie Wade, ${ }^{1}$ Amity Campbell, ${ }^{1}$ Anne Smith, ${ }^{1}$ Joanne Norcott, ${ }^{2}$ and Peter O'Sullivan ${ }^{1}$ \\ ${ }^{1}$ Curtin University; ${ }^{2}$ Ascend Physiotherapy, Perth
}

\begin{abstract}
The link between static and dynamic landing lumbar postures, when gymnasts are exposed to large ground reaction forces, has not been established. This investigation aimed to (a) determine if a relationship exists between sagittal static and dynamic landing lumbar spine angles at peak ground reaction force (GRF) and (b) quantify how close to end-range postures the gymnasts were at landing peak GRF. Twenty-one female gymnasts' upper and lower lumbar spine angles were recorded: statically in sitting and standing, during landing of three gymnastic skills, and during active end-range lumbar flexion. Pearson's correlations were used to investigate relationships between the angles in different postures. Significant correlations $(r=.77-.89, p<$ .01 ) were found between all the static/dynamic postures in the lower lumbar spine angle, while fewer and less significant upper lumbar spine correlations were reported. Thirty percent of gymnasts landed a backsault with their lower lumbar spine flexed beyond their active end-range while experiencing GRF 6.8-13.3 times their body weight. These results inform low back pain prevention and management strategies in this population and highlight areas for future research.
\end{abstract}

Keywords: gymnastics, posture, lumbar region, loading, injury

Gymnastics is an increasingly popular sport with over 5 million participants in the USA in $2010,76 \%$ being female and $80 \%$ under 18 years of age (Gymnastique, 2010). Gymnasts appear to be at significant risk of lower back injuries, reporting annual incidence between 30 and 90\% (Caine et al., 1989; Daly et al., 2001; Harringe et al., 2007; Homer \& Mackintosh, 1992; Ohlen et al., 1989; Tsai \& Wredmark, 1993). These injuries can have a significant impact on the gymnast's career, impairing the ability to train (Caine et al., 1989; Kolt \& Kirkby, 1999) and are frequently recurring, with one study reporting an annual low back pain (LBP) recurrence rate of $72 \%$ (Caine et al., 1989).

While we acknowledge that LBP risk should be considered from a biopsychosocial perspective in athletic populations (Galambos et al., 2005; O'Sullivan, 2012), several physical factors have been reported to be associated with gymnasts' risk of LBP. These include; the young starting age of participants (Gymnastique, 2010), training and competing during periods of growth (Kujala et al., 1997), excessive force exposure related to overall duration of training (Daly, et al., 2001; Dixon \& Fricker, 1993), and complexity of skills performed (Hall, 1986; Kruse \& Lemmen, 2009; Wojtys et al., 2000).

Melanie Wade, Amity Campbell (Corresponding Author), Anne Smith, and Peter O'Sullivan are with the School of Physiotherapy and Curtin Health Innovation Research Institute, Curtin University, Perth, Australia. Joanne Norcott is with Ascend Physiotherapy, Perth, Australia.
It is also generally accepted that gymnasts are most at risk for injuries, including LBP, during landing (Adams \& Dolan, 2005; Caine et al., 1989; Daly et al., 2001; Dufek \& Bates, 1989; Marshall et al., 2007; McAuley et al., 1987) where they have been reported to produce ground reaction forces up to 13 times body weight (Harringe et al., 2007). While it has been observed that gymnasts are at times in extreme lumbar postures while absorbing these high loads (Daly et al., 2001), the lumbar posture during landing has not been quantified. In contrast, a growing body of research has linked static and dynamic nonneutral spinal postures with LBP, including populations of adolescents (Smith et al., 2008), adults (Dankaerts et al., 2009), adolescent rowers ( $\mathrm{Ng}$ et al., 2008), and cyclists (Burnett et al., 2004). Furthermore, there is evidence that adopting end-range sagittal plane spinal positions results in reduced activity of the lumbopelvic stabilizing muscles, and is associated with poorer back muscle endurance (Campbell et al., 2011), therefore potentially increasing risk of lumbar spine injury under load (Cholewicki et al., 2005; Dankaerts et al., 2006; Mitchell et al., 2008). To date, no research has investigated the proximity of gymnasts landing postures to their end-range lumbar spine position.

Given the links between static spinal posture and LBP, postural assessment and training is considered to be important for LBP prevention (Perich et al., 2006). There is evidence that spinal posture can be altered with specific training in pain-free subjects (Scannell \& McGill, 2003) and that postural retraining can decrease LBP in athletic 
populations (Perich et al., 2011; Thorpe et al., 2009). However, it is unknown whether static postures correlate with dynamic loading postures; when gymnasts are at greatest risk of injury. In support of this concept, it has recently been demonstrated in female nursing students that their static sitting posture of the lower lumbar spine was correlated with the peak lower lumbar flexion angle assumed during functional tasks such as bending and lifting, suggesting that static lower lumbar spine postures may represent a signature postural base that is carried into functional tasks (Mitchell, et al., 2008). This study also identified regional differences between the upper and lower lumbar spine, suggesting that these regions should be considered separately when investigating sagittal plane movements and positions (Mitchell, et al., 2008).

Understanding the relationship between static and dynamic sporting activities could offer an avenue for identifying elevated risk for LBP and injury, enabling the introduction of preventative measures early in a gymnast's career. The aims of this study were to determine (a) whether there is a relationship between sagittal lumbar angles (lumbar/upper lumbar/lower lumbar) in static habitual postures (standing/sitting) and dynamic landing postures (drop landing/backsault/plyometric frontsault) at peak ground reaction force in female, elite gymnasts, (b) quantify regional lumbar spine postures at the peak ground reaction force (GRF) during landing, relative to active flexion maximum range of movement. It was hypothesized that (a) consistent with previous research (Mitchell, et al., 2008) a posture signature between static and dynamic regional lumbar postures would exist and (b) a cohort of pain free gymnasts would not land beyond their end-range flexion position in all three landings.

\section{Methods}

Twenty one elite female artistic gymnasts [mean (standard deviation); age 13 (3) years, height 148.1 (10.5) $\mathrm{cm}$, and mass $39.8(8.9) \mathrm{kg}$ ] from the Western Australian Institute of Sport (WAIS) and Northern Districts Gymnastics Club WA who were training greater than $20 \mathrm{hr}$ per week participated in this study. In recognition of known anatomical and spinal posture differences between males and females (Smith et al., 2008), only one gender was included in this investigation. Subjects were excluded if they had musculoskeletal injuries inhibiting training for the 6 weeks before testing, any experience of LBP within the 3 months before testing, or a history of recurring significant LBP. All participants and guardians gave informed consent following ethical approval from relevant institution human research ethics committee.

Subjects attended data collection at the Curtin University School of Physiotherapy Research Laboratory, where a 10-camera passive three-dimensional motion analysis system (Vicon; Oxford Metrics, inc.) and force plate (Advanced Mechanical Technology, inc.) were used to collect the relevant kinematic and force data. For this purpose, the Vicon system was operated at $250 \mathrm{~Hz}$, while the force plate captured at $1000 \mathrm{~Hz}$. Following arrival, participant's height and weight were recorded. They were then fitted with the lumbar and pelvic region retroreflective marker set, which included markers $(15 \mathrm{~mm}$ diameter) fixed to the skin surface overlying the $1 \mathrm{st}$, 3rd and 5 th lumbar vertebral spinous processes, $5 \mathrm{~cm}$ bilaterally of the junctions between the 1st / 2nd and 3rd/4th lumbar vertebral spinous processes and the right and left anterior and posterior superior iliac spines (Figure 1).

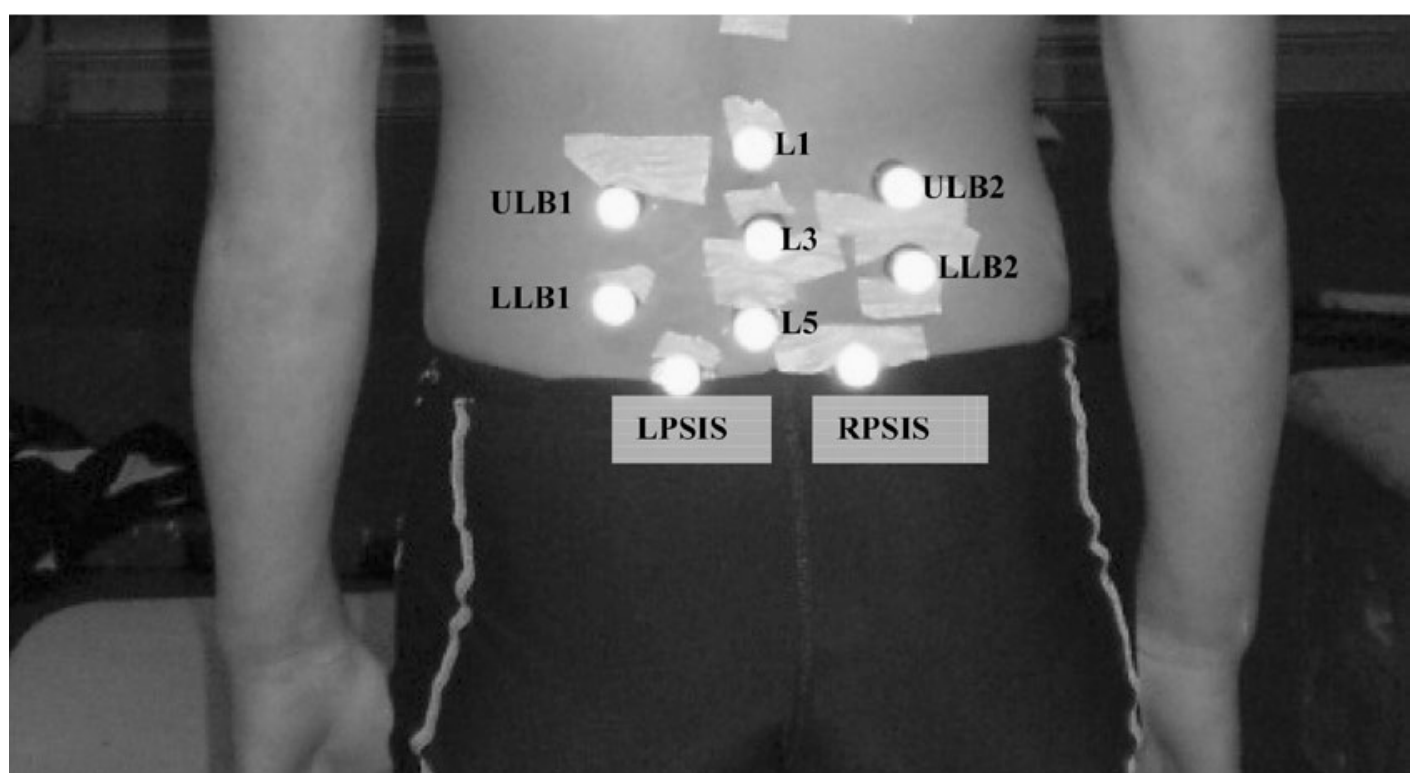

Figure 1 - The motion analysis marker set including L1, L3, L5, upper lumbar bilateral markers (ULB1 \& ULB2), lower lumbar bilateral markers (LLB1 \& LLB2), and posterior superior iliac spinal markers (LPSIS \& RPSIS). Anterior superior iliac spinal markers are not visible. 
Following a warm-up, the subjects performed three dynamic skills: drop landing (DL), back somersault (BS), and plyometric front somersault (PFS). A gymnastic coach was present at all data collections to instruct each participant on the correct execution of all dynamic trials. All participants were instructed to perform the landing from each skill as they would during training or competition, without taking a step or hop during landing (McNittGray et al., 2001). The DL required the gymnasts to step off a $1 \mathrm{~m}$ high box and land with both feet simultaneously onto the force plate. The BS was performed from a standing position on a launch pad (air-inflated mat) onto the force plate. The PFS required the gymnasts to jump from the $1 \mathrm{~m}$ high box onto the launch pad and then perform a front somersault onto the force plate. Gym mats $(5 \mathrm{~cm}$ thick) were placed on the force plate and surrounding floor to ensure the safety of participants. This will have affected the magnitude of the ground reaction force collection; however, a previous study confirmed less than $5 \%$ difference in reaction forces can be expected when mats up to $12 \mathrm{~cm}$ thick are secured to the force plate (McNitt-Gray et al., 2001). All equipment used in this investigation was acquired from a gymnastics training environment (WAIS).

The participants completed a maximum of 10 trials of each dynamic task to avoid the effects of fatigue. Trials were discarded if the participant did not land successfully, such as taking a step or falling. In accordance with previous research the average of 3-5 trials was used to represent each girl's technique (Mullineaux et al., 2001), with the exception of 3 participants who only successfully completed 2 BSs and PFSs and 1 participant who only successfully performed 1 BS and PFS. Habitual sitting and standing postures were measured following an established protocol (Mitchell et al., 2008). The participants were asked to relax as much as possible and were not told specifically when data were collected. Several recordings were then captured over a 10 -min time period. Lumbar flexion range of motion data were collected using three different movements strategies to obtain the gymnasts full flexion range of motion following previously established protocols (Mitchell et al., 2008): (1) forward bend-involved the subjects bending as far forward as possible from standing while keeping their knees straight, (2) forward bend with no pelvis movement-involved the subjects placing their hands on their hips to ensure their pelvis was stable while bending as far forward as possible, and (3) slump sit—required the gymnasts from a seated position to round their spine as much as possible while keeping their shoulders in line with their hips.

The Vicon data were analyzed in specialized Vicon motion analysis Software (Nexus; Oxford Metrics, inc). The trajectories and force plate data were filtered with a low-pass Butterworth filter using a cutoff frequency of 10 $\mathrm{Hz}$ (as determined from a residual analysis). A customized version of a previously validated 3D mathematical model for the lumbar spine (Seay et al., 2008) was used to create three segments for the lumbar spine region. (1) The Lumbar spine (Lx) Y axis was defined from the
L5 to the L1 marker, the cross product of this axis and a line connecting the two markers bilateral of the L4/L5 junction was used to create the $\mathrm{Z}$ axis, and finally the cross product of the $\mathrm{Y}$ and $\mathrm{Z}$ axes was used to create the $X$ axis. (2) The Upper lumbar region (ULx) $Y$ axis was defined from the L3 to the L1 marker, the cross product of this axis and a line connecting the two markers bilateral of the L2/L3 junction was used to create the $Z$ axis, and finally the cross product of the $\mathrm{Y}$ and $\mathrm{Z}$ axes was used to create the $X$ axis. (3) The Lower lumbar region (LLx) Y axis was defined from the L5 to the L3 marker, the cross product of this axis and a line connecting the two markers bilateral of the L4/L5 junction was used to create the $\mathrm{Z}$ axis, and finally the cross product of the $\mathrm{Y}$ and $\mathrm{Z}$ axes was used to create the $\mathrm{X}$ axis. The pelvis segment and component within the above mentioned mathematical model followed International Society of Biomechanics recommendations (Wu, 2002). A ZXY Euler angle decomposition was then used to calculate the following three angles: (1) Lx angle: Lx segment sagittal plane motion relative to the pelvis, (2) ULx angle: ULx segment sagittal plane motion relative to the pelvis, and (3) LLx angle: LLx segment sagittal plane motion relative to the pelvis. The validity of a similar passive marker set has been established (Seay, et al., 2008), with the reliability of lumbar spine measures from surface landmark based motion analysis also confirmed (Pearcy \& Hindle, 1989). Flexion in the sagittal plane was indicated by a more positive value, with extension indicated by a more negative value. These angles were output $0.1 \mathrm{~s}$ before and following peak vertical GRF and time normalized to 101 data points. This data were subsequently averaged across each subject's data and across all subjects and presented graphically. The average for each angle at the instant of peak vertical GRF for each subject's trials was also calculated for each dynamic skill for comparison with static and end-range angles.

The standing and sitting posture trials were visually inspected to identify a period of 20-30 s of stability. The standard deviation of each angle was then calculated within this $20-30 \mathrm{~s}$ period. The average posture during a 50 frame $(0.1 \mathrm{~s})$ period of time that the posture oscillated less than $1^{\circ}$ was then used to represent static posture. The maximum for the three angles during each flexion movement were extracted and the largest flexion angle from the three movements was used to represent active endrange lumbar flexion. The peak vertical GRF data were normalized for gravity and the gymnast's body weight.

Statistical analysis was carried out with SPSS v14.0 (SPSS, Chicago, IL, USA.). Statistical significance was set at $p<.05$ for all tests. From a priori power calculations it was determined a sample of 20 subjects would give $78 \%$ power to detect a correlation between static and dynamic lumbar angles of at least 0.550 at a statistical significance level of $\alpha=.05$. The relationship between the lumbar angles in standing, sitting, and dynamic landing postures was initially assessed graphically to confirm the assumption of an approximately linear relationship and the absence of unduly influential outlying values. 
The strength of each relationship was assessed using a Pearson's correlation coefficient. In describing the magnitude of the correlations, $0.0-0.1$ will be referred to as a very small relationship, $0.1-0.3$ as small, $0.3-0.5$ as moderate, $0.5-0.7$ as large, $0.7-0.9$ as very large, and 0.9-1 as a nearly perfect relationship (Hopkins, 2002). Fisher's $z$ test was used to calculate the significance of the differences between correlations. The average angular distance each participant's dynamic landing posture was from their end-range flexion was determined by subtracting each participants landing angle from their maximum flexion. Therefore, a positive value indicates a landing posture flexed beyond end of range.

\section{Results}

The results of the posture comparisons between static and dynamic trials revealed a number of strong relationships in all of the spinal angles measured (Lx, LLx and ULx). More specifically, the Lx angle displayed large to very large positive and statistically significant correlations for all relationships considered (Table 1). However, when the
Lx spine was considered as two segments, differing static/ dynamic posture associations were apparent between the two regions. Firstly, no correlation was identified between standing and sitting for the ULx angle, whereas the LLx angle displayed a very large significant positive correlation, with the difference (diff) between these ULX and LLx correlations found to be statistically significant (diff:0.931, confidence interval (CI): 0.56-0.96, $p<.001$ ). The ULx angle correlations were substantially smaller than LLx correlations for standing/ dynamic posture relationships, with only the standing/DL posture relationship identified as statistically significant for the ULx angle, whereas all LLx correlations were very large and highly significant. There was a statistically significant difference between the ULx and LLx correlations for all three standing/dynamic posture comparisons (DL diff: 0.426, CI: 0.26-0.92, p: 0.006; BS diff: 0.51, CI: 0.09-0.89, $p$ : 0.027; PFS diff: 0.455, CI: 0.26-0.92, $p$ : 0.006). The ULx angle correlations were also smaller than LLx correlations for sitting/dynamic posture relationships, but only substantially so in the case of the sitting/DL posture relationship (diff: 0.378, CI: 0.05-0.85, p: 0.070).

Table 1 The relationship (Pearson's correlations, 95\% confidence intervals and $p$-values) between sitting and standing with dynamic landing postures at the lumbar, upper lumbar, and lower lumbar spinal regions

\begin{tabular}{|c|c|c|c|c|c|}
\hline & & \multicolumn{4}{|c|}{ Lx Angle $\left({ }^{\circ}\right)$} \\
\hline & & Stand & $\mathbf{D L}$ & BS & PFS \\
\hline & Correlation & - & .823 & .514 & .765 \\
\hline \multirow[t]{3}{*}{ Stand } & $95 \% \mathrm{CI}$ & - & 0.607 to 0.926 & 0.093 to 0.780 & 0.498 to 0.900 \\
\hline & $p$-value & - & $.000 *$ & $.020 *$ & $.000^{*}$ \\
\hline & Correlation & .510 & .622 & .745 & .620 \\
\hline \multirow[t]{5}{*}{ Sit } & $95 \% \mathrm{CI}$ & 0.100 to 0.772 & 0.260 to 0.831 & 0.451 to 0.893 & 0.257 to 0.830 \\
\hline & $p$-value & $.018 *$ & $.003 *$ & $.000 *$ & $.003 *$ \\
\hline & & \multicolumn{4}{|c|}{ ULx Angle $\left({ }^{\circ}\right)$} \\
\hline & & Stand & $\mathrm{DL}$ & BS & PFS \\
\hline & Correlation & - & .464 & .263 & .424 \\
\hline \multirow[t]{3}{*}{ Stand } & $95 \% \mathrm{CI}$ & - & 0.040 to 0.746 & -0.203 to 0.632 & -0.009 to 0.723 \\
\hline & $p$-value & - & $.034 *$ & .263 & .055 \\
\hline & Correlation & -.100 & .197 & .655 & .596 \\
\hline \multirow[t]{5}{*}{ Sit } & $95 \% \mathrm{CI}$ & -0.510 to 0.347 & -0.257 to 0.579 & 0.300 to 0.851 & 0.221 to 0.817 \\
\hline & $p$-value & .667 & .391 & $.002 *$ & $.004 *$ \\
\hline & & \multicolumn{4}{|c|}{ LLx Angle $\left({ }^{\circ}\right)$} \\
\hline & & Stand & $\mathrm{DL}$ & BS & PFS \\
\hline & Correlation & - & .890 & .774 & .879 \\
\hline \multirow[t]{3}{*}{ Stand } & $95 \% \mathrm{CI}$ & - & 0.744 to 0.955 & 0.504 to 0.906 & 0.721 to 0.950 \\
\hline & $p$-value & - & $.000 *$ & $.000 *$ & $.000 *$ \\
\hline & Correlation & .831 & .769 & .845 & .766 \\
\hline \multirow[t]{2}{*}{ Sit } & $95 \% \mathrm{CI}$ & 0.623 to 0.929 & 0.505 to 0.901 & 0.643 to 0.937 & 0.499 to 0.900 \\
\hline & $p$-value & $.000 *$ & $.000 *$ & $.000 *$ & $.000^{*}$ \\
\hline
\end{tabular}

Note. Lx, lumbar; ULx, upper lumbar; LLx, lower lumbar; CI, confidence interval; DL, drop landing; BS, backsault; PFS, plyometric frontsault.

*Statistically significant $(p<0.05)$. 
The average angular distance that each participant's dynamic landing posture was from their end of active flexion range for each movement are all negative, for both the ULx and LLx, which indicates that the average landing posture was before end-range flexion (Table 2). However, the range data indicates that while no gymnasts exceeded their UL end of range, several gymnasts did land with their LLx spine flexed beyond their end of range; $4.8 \%$ ( 1 of 21) following a DL, $30 \%$ (6 of 20) following a $\mathrm{BS}$, and $9.5 \%$ ( 2 of 21 ) following a PFS, while absorbing between 5.2-12.6 times their body weight in force. The movement before and following initial ground contact further indicates the pattern of sagittal plane movement in the ULx and LLx spine (Figures 2-4). These graphs indicate that most gymnasts continue to flex in both their ULx and LLx following initial contact and throughout the absorption of the ground reaction forces.

\section{Discussion}

This is the first study to our knowledge to investigate relationships between static regional lumbar spine postures and dynamic loading postures in gymnasts. The patterns of correlations in the three different spinal segments analyzed (Lx, LLx and ULx) emphasize the importance of considering the lumbar spine as two distinct functional spinal segments. Very large correlations between the LLx angle in sitting and standing and all of the static/dynamic postures were reported. In contrast, for the ULx angle no correlation was found with the sit/stand and only a few less significant correlations were reported between the static/dynamic postures. These findings suggest that there is less individual variation in the LLx region posture but high variation in the ULx region between functional tasks. Further, the LLx and ULx appeared to travel through a similar range of motion during the functional tasks (Figures $1-3)$; it is therefore not simply a case of the LLx being more rigid than the ULx during functional tasks. These results support previous suggestions that a LLx posture signature between static and dynamic functional tasks exists, which in turn supports current clinical practice where habitual postures are often analyzed and altered in an effort to reduce pain (Gill et al., 2007; Mitchell et al., 2008). Given the high risk of injuries to the LLx in gymnasts these findings have clear clinical and future research implications.

In this study gymnasts landed with their Lx spine postured close to and/or beyond their end of range of active $\mathrm{Lx}$ flexion. Landing in spinal postures at extremes of range during gymnastics has been suggested previously (Daly et al., 2001; Hall, 1986); however, this study is the first to quantify these values. The gymnasts were also found to achieve more lumbar flexion during landing before and/or after experiencing the peak GRF (Figures 1-3); however, we did not quantify these values.

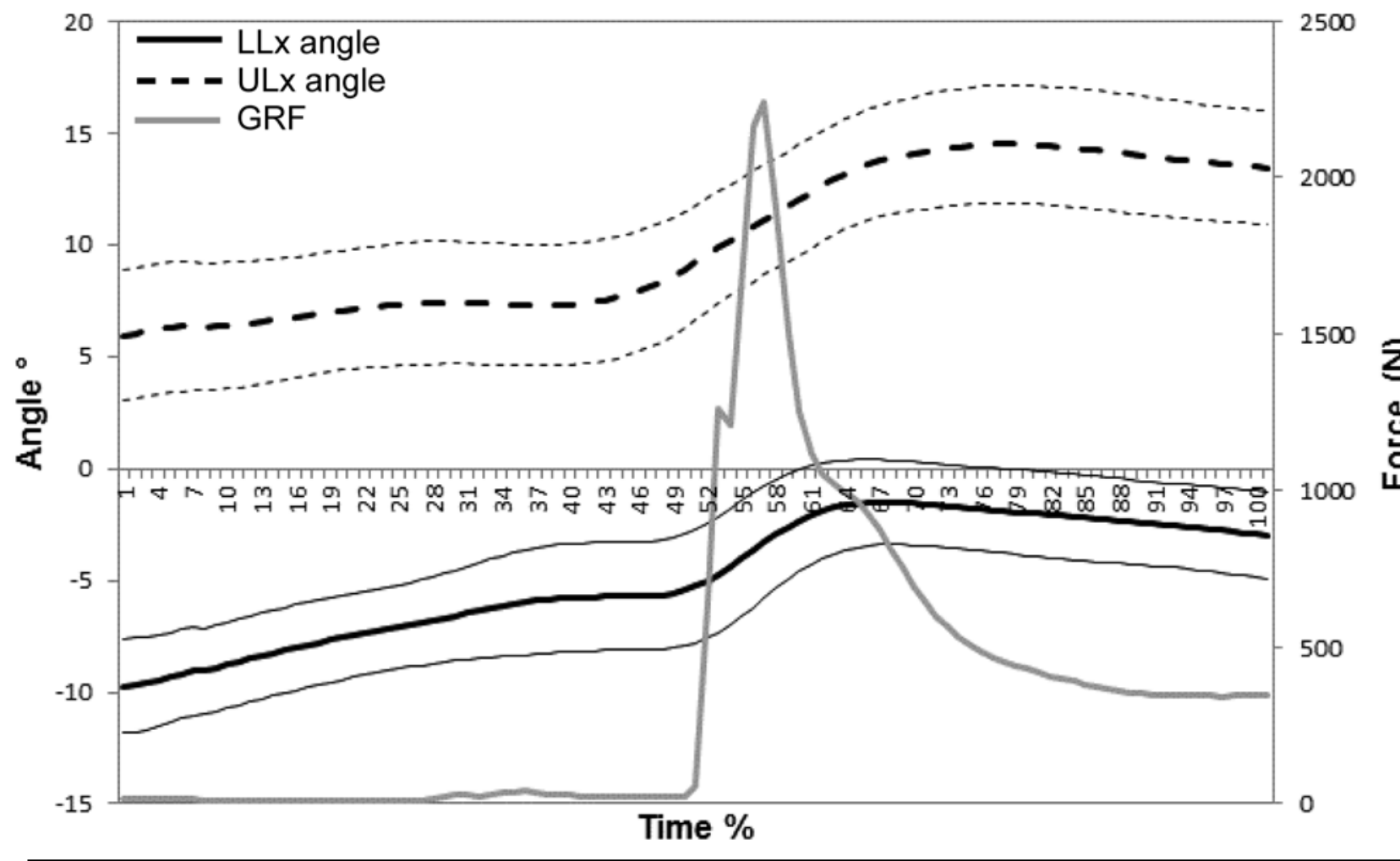

Figure 2 - The average of 21 gymnasts' average upper lumbar (ULx) and lower lumbar (LLx) angles and vertical GRF $0.1 \mathrm{~s}$ before and following ground contact from a drop landing, with two lines either side of the ensemble average representing the values $\pm S D$. 


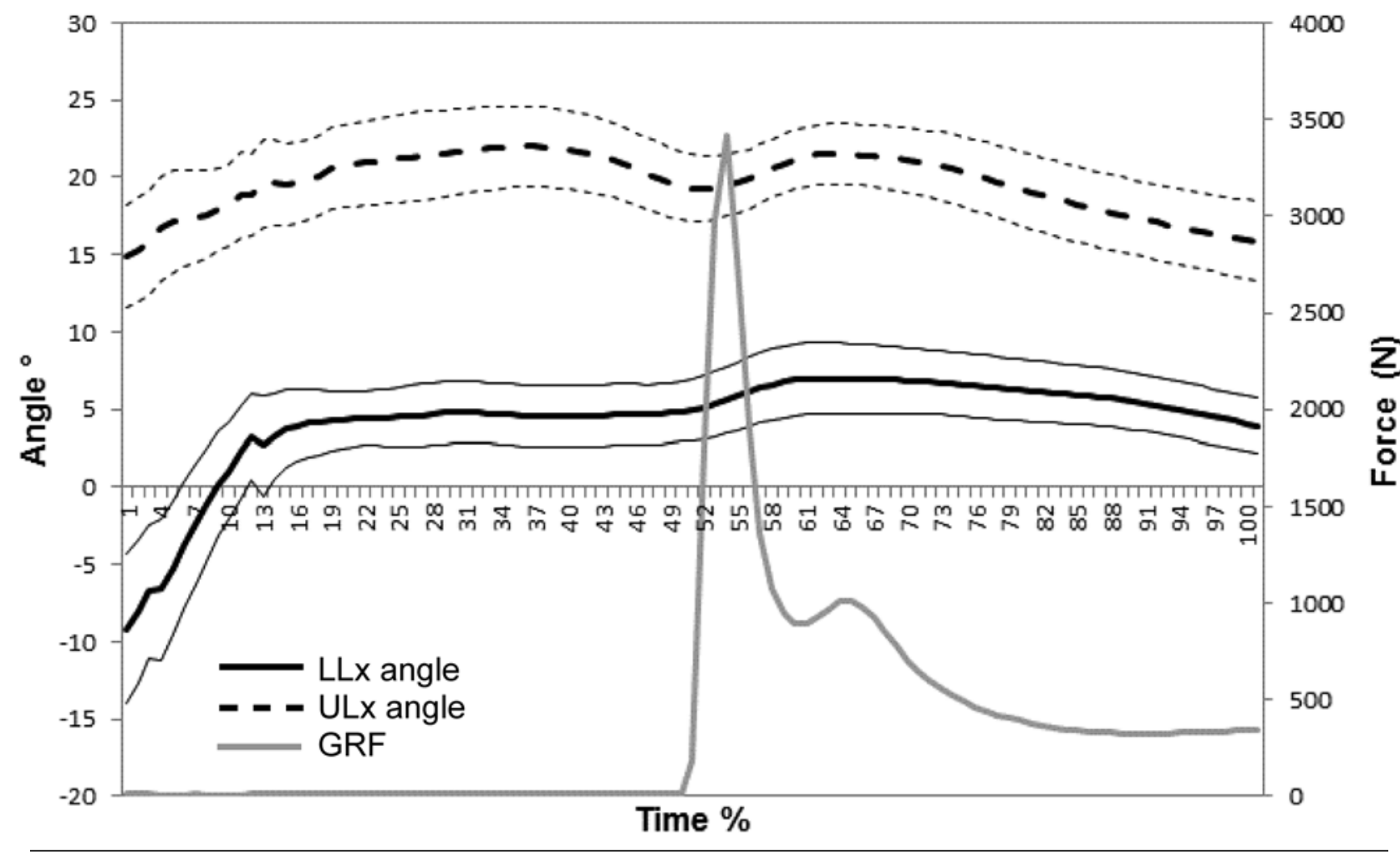

Figure 3 - The average of 21 gymnasts' average upper lumbar (ULx) and lower lumbar (LLx) angles and vertical GRF $0.1 \mathrm{~s}$ before and following ground contact from a BS, with two lines either side of the ensemble average representing the values $\pm S D$.

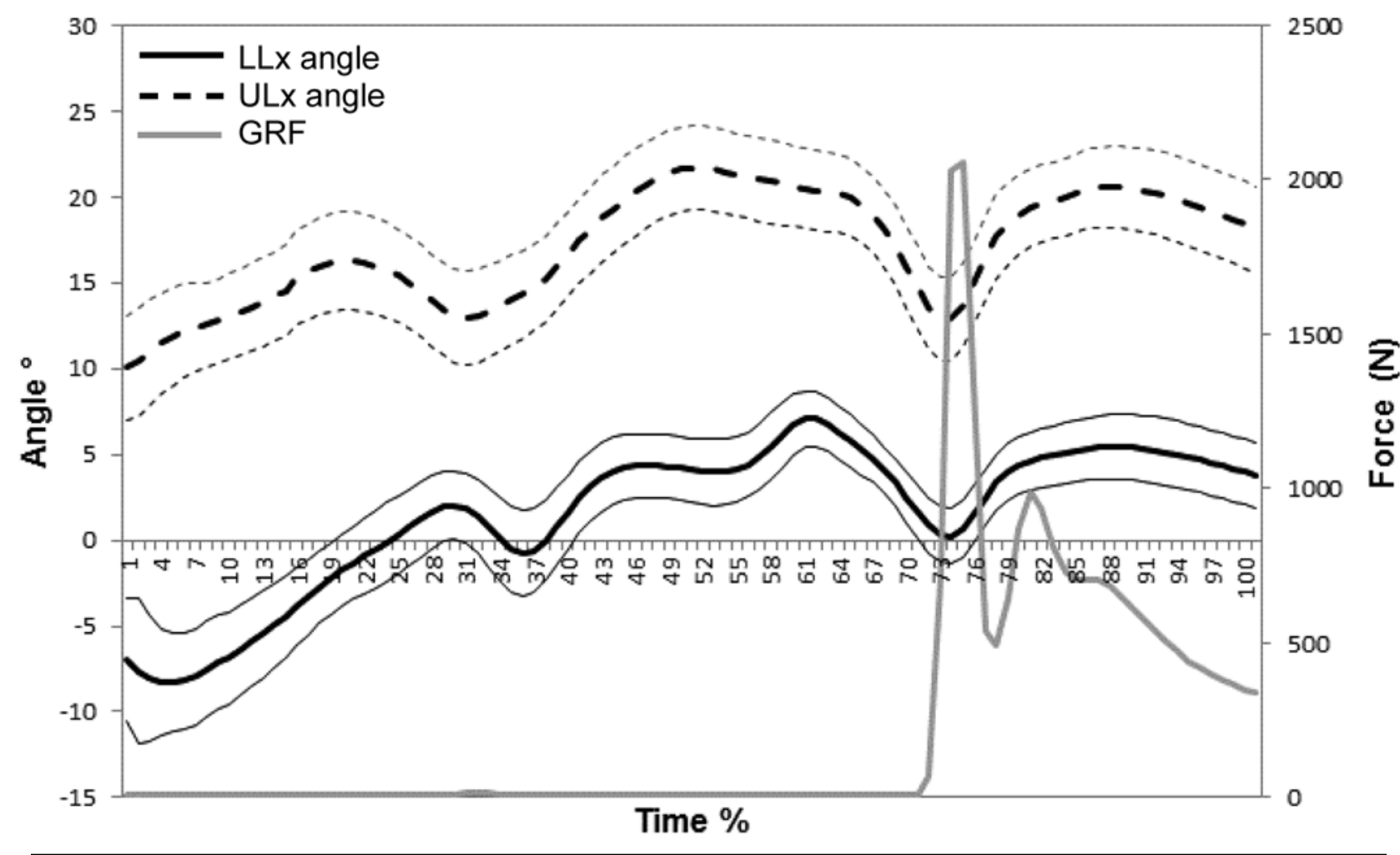

Figure 4 - The average of 21 gymnasts' average upper lumbar (ULx) and lower lumbar (LLx) angles and vertical ground reaction force GRF $0.1 \mathrm{~s}$ before and following ground contact from a PFS, with two lines either side of the ensemble average representing the values $\pm S D$. 


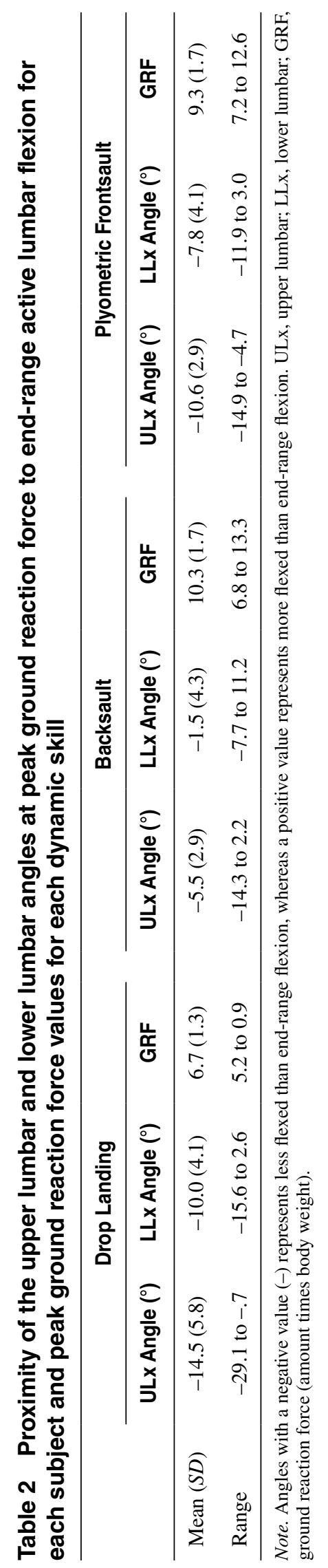


These findings may be a cause for concern, given that reduced activation of the back muscles has been shown at the end range of forward bending (Olson et al., 2004) which has been linked to increase load on lumbar discs and ligaments (Goel et al., 1993), and may leave the lumbar spine vulnerable to strain and injury (Cholewicki \& McGill, 1996).

In addition to the high frequency of end-range spinal loading when landing, the gymnasts experienced GRF five to 13 times their body weight. Previous studies have documented similar values (Harringe et al., 2007; Panzer et al., 1988), which are significantly high compared with other athletic pursuits such as cricket fast bowling and running that result in GRF up to 5 and 3 times body weight respectively (Cavanagh \& Lafortune, 1980; Foster et al., 1989; Munro et al., 1987; Nilsson \& Thorstensson, 1989). Therefore, the gymnasts are landing in extreme LLx spinal postures while experiencing large GRF, which potentially places them at high risk of lower back strain and injury. End of range sagittal plane flexion postures have been associated with LBP in rowers (Ng et al., 2008) and cyclists (Burnett et al., 2004) as well as with bending/lifting injuries in males (Olson et al., 2004). Repetitive adoption of nonneutral spinal postures, repetitive compressive loading, and the combination of flexion with loading has been proposed to be linked to lower back problems in gymnasts (Hall, 1986; Kujala et al., 1997; McAuley et al., 1987). Future longitudinal research is required to investigate whether these factors are linked to injury risk. These findings also offer a potential direction for intervention studies, which may lead to reduced LBP prevalence in this population.

These findings have a number of potential clinical implications. Firstly, regional differences should be considered when analyzing both static and dynamic lumbar spine posture in both clinical, coaching and research settings. This was confirmed in this study by the identification of differences in correlations between static and dynamic postures in the upper versus lower lumbar spine. Secondly, the findings of this study support previous work (Dankaerts et al., 2006; Mitchell et al., 2008) proposing the presence of a posture signature, where the static posture of the LLx is highly predictive of spinal postures during dynamic and even complex loading postural tasks. These findings are significant given that the majority of LBP disorders associated with identified spinal pathology (such as disc prolapse, stress fracture, and spondylolisthesis (Engstrom \& Walker, 2007)) reported in gymnasts (Tertti et al., 1990) are related to the LLx spine. The significance of these findings in these young female gymnasts is heightened by the additional evidence of low levels of variance in the LLx postures across tasks, as well as the high frequency of beyond endrange flexion loading under high levels of vertical GRF up to 13 times body weight. This combination of factors is likely to amplify the risk for LLx spine injury in these young athletes. Further research is required to investigate if this combination of factors are related to LBP and spine pathology, such as stress fractures and disc injuries, and whether training habitual static spinal postures to influence dynamic postures is effective (O'Sullivan, 2005). If so greater attention should be directed to habitual static postures outside training periods for athletes, to influence spinal motor control while performing complex dynamic postural tasks. Although there is growing evidence to support a cognitive functional approach to managing LBP in both athletic (Perich et al., 2011; Thorpe et al., 2009) and nonathletic populations (Fersum et al., 2010), further research is required to validate these concepts.

Due to the elite athletic status of this population, the small sample size, and the inclusion of females only, these results cannot be generalized over a broader gymnastic or general population. The laboratory environment also reduced the ecological validity when attempting to record typical landing and habitual postures. However, this effect, common to all laboratory investigations, might have been less evident in the current population, given that these athletes are used to training and competing in various gymnasiums while being viewed. This study was unable to accurately assess extension range of motion or extension skills, which have been linked with lumbar spine injuries (Hall, 1986), which should be considered for future research.

\section{References}

Adams, M., \& Dolan, P. (2005). Spine biomechanics. Journal of Biomechanics, 38, 1972-1983. PubMed doi:10.1016/j. jbiomech.2005.03.028

Burnett, A.F., Cornelius, M.W., Dankaerts, W., \& O'Sullivan, P.B. (2004). Spinal kinematics and trunk muscle activity in cyclists: a comparison between healthy controls and non-specific chronic low back pain subjects - a pilot investigation. Manual Therapy, 9, 211-219. PubMed doi:10.1016/j.math.2004.06.002

Campbell, A.C., Briggs, A.M., O’Sullivan, P.B., Smith, A.J., Burnett, A.F., Moss, P., . . .. (2011). An exploration of the relationship between back muscle endurance and familial, physical, lifestyle, and psychosocial factors in adolescents and young adults. The Journal of Orthopaedic and Sports Physical Therapy, 41, 486-495. PubMed

Caine, D., Cochrane, B., Caine, C., \& Zemper, E. (1989). An epidemiologic investigation of injuries affecting young competitive female gymnasts. American Journal of Sports Medicine, 17, 811-820. PubMed doi:10.1177/036354658901700616

Cavanagh, P.R., \& Lafortune, M.A. (1980). Ground reaction forces in distance running. Journal of Biomechanics, 13, 397-406. PubMed doi:10.1016/0021-9290(80)90033-0

Cholewicki, J., \& McGill, S.M. (1996). Mechanical stability of the in vivo lumbar spine: implications for injury and chronic low back pain. Clinical Biomechanics (Bristol, Avon), 11, 1-15. PubMed doi:10.1016/02680033(95)00035-6

Cholewicki, J., Silfies, S.P., Shah, R.A., Greene, H.S., Reeves, N.P., Alvi, K., . . .. (2005). Delayed trunk muscle reflex responses increase the risk of low back injuries. Spine, 30, 2614-2620. PubMed doi:10.1097/01. brs.0000188273.27463.bc

Daly, R., Bass, S., \& Finch, C. (2001). Balancing the risk of injury to gymnasts: how effective are the counter 
measures? British Journal of Sports Medicine, 35, 8-20. PubMed doi:10.1136/bjsm.35.1.8

Dankaerts, W., O'Sullivan, P., Burnett, A., Straker, L., Davey, P., \& Gupta, R. (2009). Discriminating healthy controls and two clinical subgroups of nonspecific chronic low back pain patients using trunk muscle activation and lumbosacral kinematics of postures and movements: a statistical classification model. Spine (Phila Pa 1976), $34,1610-1618$.

Dankaerts, W., O’Sullivan, P., Burnett, A., \& Straker, L. (2006). Altered Patterns of Superficial Trunk Muscle Activation During Sitting in Nonspecific Chronic Low Back Pain Patients: Importance of Subclassification. Spine, 31, 20172023. PubMed doi:10.1097/01.brs.0000228728.11076.82

Dixon, M., \& Fricker, P. (1993). Injuries to elite gymnasts over $10 \mathrm{yr}$. Medicine and Science in Sports and Exercise, 25, 1322-1329. PubMed doi:10.1249/00005768-19931200000002

Dufek, J., \& Bates, B. (1989). The evaluation and prediction of impact forces during landings. Medicine and Science in Sports and Exercise, 22, 370-377. PubMed

Engstrom, C.M., \& Walker, D.G. (2007). Pars interarticularis stress lesions in the lumbar spine of cricket fast bowlers. Medicine and Science in Sports and Exercise, 39, 28-33. PubMed doi:10.1249/01.mss.0000241642.82725.ac

Fersum, K., O’Sullivan, P., Kvale, A., \& Skeoun, J. (2010). Efficacy of classification based "cognitive functional therapy' in patients with Non-Specific Chronic Low Back Pain - A randomized controlled trial. Paper presented at the 7th Interdisciplinary World Congress on Low Back and Pelvic Pain, The United States of America.

Foster, D., John, D., Elliott, B., Ackland, T., \& Fitch, K. (1989). Back injuries to fast bowlers in cricket: a prospective study. British Journal of Sports Medicine, 23, 150-154. PubMed doi:10.1136/bjsm.23.3.150

Galambos, S.A., Terry, P.C., Moyle, G.M., Locke, S.A., \& Lane, A.M. (2005). Psychological predictors of injury among elite athletes. British Journal of Sports Medicine, 39, 351-354, discussion 351-354. PubMed doi:10.1136/ bjsm.2005.018440

Gill, K.P., Bennett, S.J., Savelsbergh, G.J.P., \& van Dieen, J.H. (2007). Regional changes in spine posture at lift onset with changes in lift distance and lift style. Spine, 32, 1599-1604. PubMed doi:10.1097/BRS.0b013e318074d492

Goel, V.K., Kong, W.Z., Han, J.S., Weinstein, J.N., \& Gilbertson, L.G. (1993). A combined finite-element and optimization investigation of lumbar spine mechanics with and without muscles. Spine, 18, 1531-1541. PubMed

Gymnastique, F.I.d. (2010). Fédération Internationale de Gymnastique. Retrieved 10 March, 2010, from http://www. fig-gymnastics.com/

Hall, S.J. (1986). Mechanical Contribution to Lumbar Stress Injuries in Female Gymnasts. Medicine and Science in Sports and Exercise, 18, 599-602. PubMed doi:10.1249/00005768-198612000-00001

Harringe, M., Nordgren, J., Arvidsson, I., \& Werner, S. (2007). Low back pain in young female gymnasts and the effect of specific segmental muscle control exercises of the lumbar spine: a prospective controlled intervention study. Knee Surgery, Sports Traumatology, Arthroscopy, 15, 1264-1271. PubMed doi:10.1007/s00167-007-0289-9

Homer, S., \& Mackintosh, S. (1992). Injuries in young female elite gymnasts. Physiotherapy, 78, 804-808. doi:10.1016/ S0031-9406(10)60449-X
Hopkins, W. (2002). A new view of statistics. A scale of magnitudes for effect statistics Retrieved 27 August, 2010, from http://www.sportsci.org/resource/stats/index.html

Kolt, G., \& Kirkby, R. (1999). Epidemiology of injury in elite and subelite female gymnasts: a comparison of retrospective and prospective findings. British Journal of Sports Medicine, 33, 312-318. PubMed doi:10.1136/ bjsm.33.5.312

Kruse, D., \& Lemmen, B. (2009). Spine injuries in the sport of gymnastics. Current Sports Medicine Reports, 8, 20-28. PubMed

Kujala, U., Taimela, S., Oksanen, A., \& Salminen, J. (1997). Lumbar Mobility and Low Back Pain During Adolescence. American Journal of Sports Medicine, 25, 363-368. PubMed doi:10.1177/036354659702500316

Marshall, S.W., Covassin, T., Dick, R., Nassar, L.G., \& Agel, J. (2007). Descriptive epidemiology of collegiate women's gymnastics injuries: National Collegiate Athletic Association injury surveillance system, 1988-1989 through 20032004. Journal of Athletic Training, 42, 234-240. PubMed

McAuley, E., Hudash, G., Shields, K., Albright, J., Garrick, J., Requa, R., . . .. (1987). Injuries in women's gymnastics. American Journal of Sports Medicine, 15, 558-565. PubMed doi:10.1177/036354658701500607

McNitt-Gray, J.L., Hester, D.M.E., Mathiyakom, W., \& Munkasy, B.A. (2001). Mechanical demand and multijoint control during landing depend on orientation of the body segments relative to the reaction force. Journal of Biomechanics, 34, 1471-1482. PubMed doi:10.1016/ S0021-9290(01)00110-5

Mitchell, T., O'Sullivan, P. B., Burnett, A. F., Straker, L., \& Smith, A. (2008). Regional differences in lumbar spinal posture and the influence of low back pain. Biomed Central: Musculoskeletal Disorders, 9.

Mullineaux, D., Bartlett, R., \& Bennett, S. (2001). Research design and statistics in biomechanics and motor control. Journal of Sports Sciences, 19, 739-760. PubMed doi: 10.1080/026404101317015410

Munro, C.F., Miller, D.I., \& Fuglevand, A.J. (1987). Ground reaction forces in running - a reexamination. Journal of Biomechanics, 20, 147-155. PubMed doi:10.1016/0021-9290(87)90306-X

Ng, L., Burnett, A., \& O'Sullivan, P. (2008). Spino-pelvic kinematics and trunk muscle activation in prolonged ergometer rowing: mechanical etiology of non-specific low back pain in adolescent rowers.

Nilsson, J., \& Thorstensson, A. (1989). Ground reaction forces at different speeds of human walking and running. Acta Physiologica Scandinavica, 136, 217-227. PubMed doi:10.1111/j.1748-1716.1989.tb08655.x

O'Sullivan, P. (2005). Diagnosis and classification of chronic low back pain disorders: Maladaptive movement and motor control impairments as underlying mechanism. Manual Therapy, 10, 242-255. PubMed doi:10.1016/j. math.2005.07.001

O'Sullivan, P. (2012). It's time for change with the management of non-specific chronic low back pain. British Journal of Sports Medicine, 46, 224-227. PubMed

Ohlen, G., Wredmark, T., \& Spangfort, E. (1989). Spinal Sagittal Configuration and Mobility Related To Low-back-pain in the Female Gymnast. Spine, 14, 847-850. PubMed doi:10.1097/00007632-198908000-00013

Olson, M.W., Li, L., \& Solomonow, M. (2004). Flexionrelaxation response to cyclic lumbar flexion. Clinical 
Biomechanics (Bristol, Avon), 19, 769-776. PubMed doi:10.1016/j.clinbiomech.2004.05.007

Panzer, V., Wood, G., Bates, B., \& Mason, B. (1988). Lower extremity loads in landings of elite gymnasts. In G. de Groot, A. Hollander, P. Huijing, \& G. van Ingen Schenau (Eds.), Biomechanics XI (pp. 727-735). Amsterdam: Free University Press.

Pearcy, M., \& Hindle, R. (1989). New method for the noninvasive three-dimensional measurement of the human back movement. Clinical Biomechanics (Bristol, Avon), 4, 73-79. doi:10.1016/0268-0033(89)90042-9

Perich, D., Burnett, A., \& O’Sullivan, P. (2006). Low back pain and the factors associated with it: Examination of adolescent female rowers. Paper presented at the XXIVth Symposium on Biomechanics in Sports.

Perich, D., Burnett, A., O'Sullivan, P., \& C, P. (2011). Low back pain in adolescent female rowers: a multi-dimensional intervention study. Knee Surgery, Sports Traumatology, Arthroscopy, in press 5.10.

Scannell, J.P., \& McGill, S.M. (2003). Lumbar posture - should it, and can it, be modified? A study of passive tissue stiffness and lumbar position during activities of daily living. Physical Therapy, 83, 907-917. PubMed

Seay, J., Selbie, S., \& Hamill, J. (2008). In vivo lumbo-sacral forces and moments during constant speed running at different stride lengths. Journal of Sports Sciences, 26, 1519-1529. PubMed
Smith, A., O'Sullivan, P., \& Straker, L. (2008). Classification of sagittal thoraco-lumbo-pelvic alignment of the adolescent spine in standing and its relationship to low back pain. Spine, 33, 2101-2107. PubMed doi:10.1097/ BRS.0b013e31817ec3b0

Tertti, M., Paajanen, H., Kujala, U.M., Alanen, A., Salmi, T.T., \& Kormano, M. (1990). Disc degeneration in young gymnasts. A magnetic resonance imaging study. American Journal of Sports Medicine, 18, 206-208. PubMed doi:10.1177/036354659001800216

Thorpe, A., O'Sullivan, P., Burnett, A., \& Caneira, J. (2009). The efficacy of a specific physiotherapy intervention for the prevention of low back pain in female adolescent rowers: a field study. New Zealand Journal of Sports Medicine, 36, 38-46.

Tsai, L., \& Wredmark, T. (1993). Spinal Posture, Sagittal Mobility, and Subjective Rating of Back Problems in Former Female Elite Gymnasts. Spine, 18, 872-875. PubMed doi:10.1097/00007632-199306000-00010

Wojtys, E., Ashton-Miller, J., Huston, L., \& Moga, P. (2000). The Association Between Athletic Training Time and the Sagittal Curvature of the Immature Spine. American Journal of Sports Medicine, 28, 490-498. PubMed

$\mathrm{Wu}, \mathrm{G}$. (2002). ISB recommendation on definitions of joint coordinate system of various joints for the reporting of human joint motion-part I: ankle, hip, and spine. Journal of Biomechanics, 35, 543-548. PubMed doi:10.1016/ S0021-9290(01)00222-6 